\title{
A NONSTATIONARY ITERATIVE PROCESS FOR NONEXPANSIVE MAPPINGS
}

\author{
C. W. GROETSCH
}

\begin{abstract}
It is shown that a nonstationary analogue of an iterative process of Kirk serves to approximate fixed points of compact nonexpansive mappings defined on convex subsets of a uniformly convex space.
\end{abstract}

In a recent note Kirk [1] investigated an iterative process for approximating fixed points of nonexpansive mappings defined on convex subsets of a uniformly convex Banach space. A mapping $T$ is called nonexpansive if $\|T x-T y\| \leqq\|x-y\|$ for each $x$ and $y$ in the domain of $T$.

Specifically, the iterative process studied by Kirk is given by

$$
x_{n+1}=\alpha_{0} x_{n}+\alpha_{1} T x_{n}+\cdots+\alpha_{k} T^{k} x_{n}
$$

where $\alpha_{i} \geqq 0, \alpha_{1}>0$ and $\sum_{i=0}^{k} \alpha_{i}=1$.

It is the purpose of this note to show that a nonstationary analogue of the process (1) also serves to approximate fixed points of $T$ under certain circumstances. We will make use of the fact that in a uniformly convex space with modulus of convexity $\delta$, for given $\varepsilon>0, d>0$ and $\alpha \in[0,1]$ the inequalities

$$
\|w\| \leqq\|u\| \leqq d \quad \text { and } \quad\|u-w\| \geqq \varepsilon
$$

imply that

$$
\|(1-\alpha) u+\alpha w\| \leqq\|u\|[1-2 \delta(\varepsilon / d) \min (\alpha, 1-\alpha)]
$$

(see e.g. [2, p. 4]).

LEMMA 1. If $\left\{u_{n}\right\}$ and $\left\{w_{n}\right\}$ are sequences in a uniformly convex space with $\left\|w_{n}\right\| \leqq\left\|u_{n}\right\|$ and

$$
u_{n+1}=\left(1-\alpha_{n}\right) u_{n}+\alpha_{n} w_{n} \quad\left(0 \leqq \alpha_{n} \leqq 1\right)
$$

Received by the editors May 29, 1973.

AMS (MOS) subject classifications (1970). Primary 47H10, 47H99; Secondary $65 \mathrm{~J} 05$.

Key words and phrases. Nonexpansive mapping, fixed point, uniformly convex space, iterative process.

(C) American Mathematical Society 1974 
where $\sum \min \left(\alpha_{n}, 1-\alpha_{n}\right)=\infty$, then $0 \in \operatorname{cl}\left\{u_{n}-w_{n}\right\}$ (cl $A$ denotes the (strong) closure of the set $A$ ).

Proof. Suppose $\left\|u_{n}-w_{n}\right\| \geqq \varepsilon$ for all $n$, then

$$
\begin{aligned}
\left\|u_{n+1}\right\| & =\left\|\left(1-\alpha_{n}\right) u_{n}+\alpha_{n} w_{n}\right\| \\
& \leqq\left\|u_{n}\right\|\left[1-2 \delta\left(\varepsilon /\left\|u_{1}\right\|\right) \min \left(\alpha_{n}, 1-\alpha_{n}\right)\right] .
\end{aligned}
$$

Inductively we have

$$
\left\|u_{n}\right\| \leqq\left\|u_{1}\right\| \prod_{i=1}^{n-1}\left[1-2 \delta\left(\varepsilon /\left\|u_{1}\right\|\right) \min \left(\alpha_{i}, 1-\alpha_{i}\right)\right] \text { for } n>1 .
$$

But since $\sum \min \left(\alpha_{i}, 1-\alpha_{i}\right)=\infty$, the product on the right diverges to zero and hence $\lim \left\|u_{n}\right\|=\lim \left\|w_{n}\right\|=0$ and this contradiction completes the proof.

Let the sequences $\left\{\alpha_{i j}\right\}_{i=0}^{\infty}(j=0,1, \cdots, k)$ satisfy $0 \leqq \alpha_{i j}, 0<\alpha \leqq \alpha_{i 1}$, $\sum_{j=0}^{k} \alpha_{i j}=1$ for each $i$ and $\sum \min \left(\alpha_{i 0}, 1-\alpha_{i 0}\right)=\infty$. Define operators $S_{i}$ by

$$
S_{i}=\alpha_{i 0} I+\alpha_{i 1} T+\cdots+\alpha_{i k} T^{k}, \quad i=0,1,2, \cdots .
$$

A nonstationary analogue of (1) is the process

$$
x_{n+1}=S_{n} x_{n}, \quad n=0,1,2, \cdots .
$$

Note that if $p$ is a fixed point of $T$ then

$$
\begin{aligned}
\left\|x_{n+1}-p\right\| & =\left\|\sum_{j=0}^{k} \alpha_{n j}\left(T^{j} x_{n}-T^{j} p\right)\right\| \\
& \leqq\left\|x_{n}-p\right\|
\end{aligned}
$$

and hence to establish the convergence of $\left\{x_{n}\right\}$ to a fixed point $p$ it is enough to show that some subsequence of $\left\{x_{n}\right\}$ converges to $p$.

LEMMA 2. Let $K$ be a convex subset of a uniformly convex space. If $T$ is a nonexpansive mapping of $K$ into itself which has at least one fixed point and $\left\{x_{n}\right\}$ is defined by (2), then $0 \in \operatorname{cl}\left\{x_{n+1}-x_{n}\right\}$.

Proof. Let $p$ be a fixed point of $T$ and let

We then have

$$
u_{n}=x_{n}-p \quad \text { and } \quad w_{n}=\frac{1}{1-\alpha_{n 0}} \sum_{j=1}^{k} \alpha_{n j}\left(T^{j} x_{n}-T^{j} p\right) .
$$

$$
u_{n+1}=S_{n} x_{n}-p=\alpha_{n 0} u_{n}+\left(1-\alpha_{n 0}\right) w_{n}
$$

and $\left\|w_{n}\right\| \leqq\left\|u_{n}\right\|$ since $T$ is nonexpansive. Thus, by Lemma 1 , 
$0 \in \operatorname{cl}\left\{u_{n}-w_{n}\right\}$. Also

$$
\begin{aligned}
\left\|u_{n}-w_{n}\right\| & =\left\|x_{n}-p-\frac{1}{1-\alpha_{n 0}} \sum_{j=1}^{k} \alpha_{n j} T^{j} x_{n}+p\right\| \\
& =\left\|x_{n}-\frac{1}{1-\alpha_{n 0}} \sum_{j=0}^{k} \alpha_{n j} T^{j} x_{n}+\frac{\alpha_{n 0}}{1-\alpha_{n 0}} x_{n}\right\| \\
& =\frac{1}{1-\alpha_{n 0}}\left\|x_{n}-x_{n+1}\right\| \geqq\left\|x_{n}-x_{n+1}\right\|
\end{aligned}
$$

and therefore there is a subsequence $\left\{x_{n_{i}}\right\}$ with $x_{n_{i}+1}-x_{n_{i}} \rightarrow 0$.

We now give a generalization of Kirk's result on strong convergence of the sequence $\left\{x_{n}\right\}$ defined by (1).

THEOREM. Suppose, in addition to the hypotheses of Lemma 2, that $T$ is compact. Then for each $x_{1} \in K$ the sequence $\left\{x_{n}\right\}$ defined by (2) converges to a fixed point of $T$.

Proof. By Lemma 2 there is a subsequence $\left\{x_{n_{i}}\right\}$ with $x_{n_{i}+1}-x_{n_{i}} \rightarrow 0$. Since $\alpha_{n_{i}} \in[0,1]$ and $\alpha_{n_{i}} \geqq \alpha>0$ we may assume by successively choosing subsequences $\left\{\alpha_{n_{v} j}\right\}$ of the sequences $\left\{\alpha_{n_{i}}\right\}$ that $\lim _{v} \alpha_{n_{v} j}=\alpha_{j} \in[0,1]$ where $\alpha_{1}>0$. Let

$$
S=\alpha_{0} I+\alpha_{1} T+\cdots+\alpha_{k} T^{k} .
$$

We then have

$$
x_{n_{v}}-S x_{n_{v}}=x_{n_{\nu}}-S_{n_{\nu}} x_{n_{v}}+S_{n_{v}} x_{n_{v}}-S x_{n_{v}}
$$

where $x_{n_{v}}-S_{n_{v}} x_{n_{v}}=x_{n_{v}}-x_{n_{v}+1} \rightarrow 0$.

If $p$ is a fixed point of $T$ then we have by use of (3)

$$
\left\|T^{j} x_{n_{v}}-p\right\|=\left\|T^{j} x_{n_{v}}-T^{j} p\right\| \leqq\left\|x_{n_{v}}-p\right\| \leqq\left\|x_{1}-p\right\| .
$$

Hence if we set $M=\left\|x_{1}-p\right\|+\|p\|$, then $\left\|T^{j} x_{n_{v}}\right\| \leqq M$ for all $\nu$ and each $=0, \cdots, k$. Therefore

$$
\begin{aligned}
\left\|S_{n_{v}} x_{n_{v}}-S x_{n_{v}}\right\| & =\left\|\sum_{j=0}^{k}\left(\alpha_{n_{v} j}-\alpha_{j}\right) T^{j} x_{n_{\nu}}\right\| \\
& \leqq M \sum_{j=0}^{k}\left|\alpha_{n_{v} j}-\alpha_{j}\right| \rightarrow 0 \text { as } \nu \rightarrow \infty .
\end{aligned}
$$

It follows that $x_{n_{v}}-S x_{n_{v}} \rightarrow 0$ as $\nu \rightarrow \infty$. Since $T$ is compact $I-S$ maps closed bounded subsets into closed subsets (see Kirk's argument in the Corollary to Theorem 2 of [1]). By (3) $\operatorname{cl}\left\{x_{n}\right\}$ is bounded and closed and we have shown that $0 \in(I-S) \operatorname{cl}\left\{x_{n}\right\}$. Thus there is a $z \in \operatorname{cl}\left\{x_{n}\right\}$ with 
$z-S z=0$. By [1, Theorem 1] $z$ is a fixed point of $T$ and since $z \in \operatorname{cl}\left\{x_{n}\right\}$ it follows from (3) that $x_{n} \rightarrow z$ as $n \rightarrow \infty$, completing the proof.

\section{REFERENCES}

1. W. A. Kirk, On successive approximations for nonexpansive mappings in Banach spaces, Glasgow Math. J. 12 (1971), 6-9. MR 45 \#7553.

2. Z. Opial, Nonexpansive and monotone mappings in Banach spaces, Lecture Notes 67-1, Division of Applied Mathematics, Brown University, Providence, R.I., 1967.

Department of Mathematics, University of Cincinnati, Cincinnati, Ohio 45221 